\title{
Ocular and nervous system involvement in angioma serpiginosum
}

\author{
P. C. GAUTIER-SMITH, M. D. SANDERS, AND \\ K. V. SANDERSON
}

From the National Hospital for Nervous Diseases, Queen Square, and Department of Dermatology, St. George's Hospital, London

Cutaneous angiomata of the "port wine" variety are frequently associated with angiomata elsewhere in the body and particularly in the central nervous system. Retinal and nervous system involvement by angioma serpiginosum has, however, not previously been recorded. For this reason and also because of the unusual retinal abnormality in this patient, it is felt justifiable to report this single case, which may represent a new syndrome.

\section{Case report}

A woman, born on March 13, 1929, was first admitted to the National Hospital, in July, 1950, under the care of the late Dr. J. St C. Elkington. Her parents, four sisters, and three brothers were all alive and well and there was no family history of neurological illness or of cutaneous naevi.

\section{History}

At birth her skin was normal, but at the age of I year some angiomatous lesions were noted on the right leg. At 5 years these were more extensive and at the age of 7 years they were treated by cautery. At age 17 the patient underwent an appendicectomy and the right pupil was reported to be larger than the left. At the age of 21 years (1950) she suddenly became aware of difficulty in elevating her right arm and over the next few months noticed clumsiness in the execution of fine movements with the right hand.

In the following years, the right arm became progressively weaker with impaired sensation in the hand and in 1962 she experienced attacks of burning pain in the upper arm lasting several hours. She also noted a sensation of fullness in the right orbit on bending down. The cutaneous angioma now involved the trunk, and new lesions appeared in the right axilla and on the adjacent medial aspect of the right arm.

In 1965 she first developed burning pain in the right side of the face, which persisted as did the attacks of pain in the right arm. The weakness of the right arm progressed and elevation became impossible without assistance. At about this time, she also began to experience attacks in which she would feel faint and occasionally fall to the ground. These episodes became more frequent, and occurred as often as four or five times a day, and though some were spontaneous others were precipitated by getting up suddenly or turning the head to the right.

In 1969 , she developed nocturnal paraesthesiae in the left hand; the carpal-tunnel syndrome was diagnosed and the symptoms were relieved by surgical decompression. No change was noted in October, 1970, and she was still able to work as a hospital telephonist.

The only ocular symptom reported has been of mild deterioration of vision in the right eye. 


\section{Examination}

Detailed examination was first carried out in July, 1950, and was repeated at intervals, the last occasion being in October, 1970. Angiomatous changes involved the retina, orbit, nervous system, and the skin on the right side.

S K I N

In I950, the skin lesions affected the right leg up to the level of the inguinal ligament; there was also a small lesion on the right forearm. New areas of involvement appeared in the next 15 years. In October, 1970, the right leg, lower abdomen, and buttock were extensively affected (Fig. I). The right axilla, arm, cheek, and forehead showed smaller areas with less conspicuous changes.
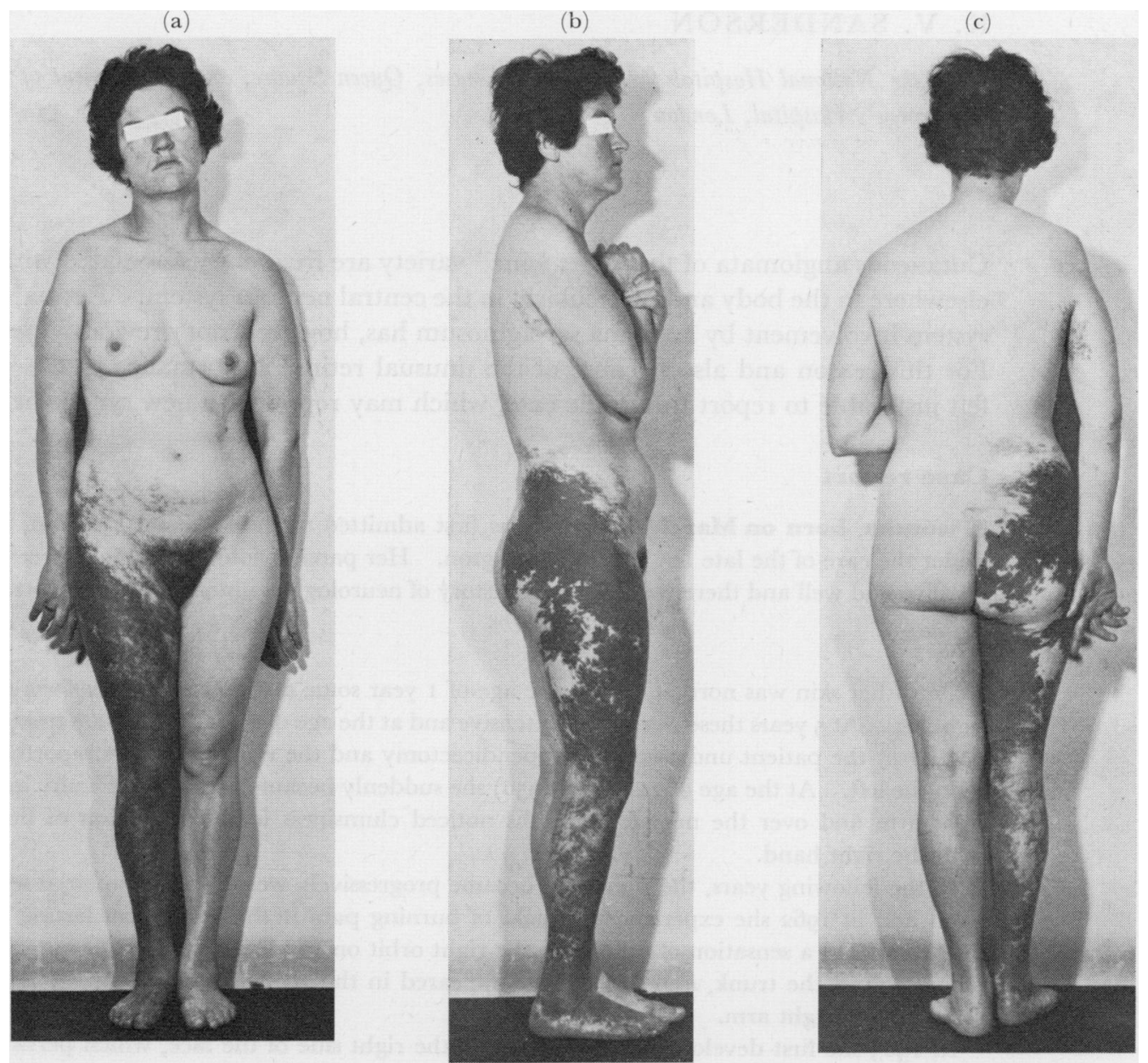

FIG. I General appearance of patient in October, 1970, showing distribution of cutaneous lesions, and muscle wasting affecting the deltoid and forearm muscles

The lesions in the different areas had the same basic appearance. They consisted of pinpoint to I mm. livid or red macules which could not be completely blanched by firm and continuous pressure (Fig. 2). The puncta were closely related, being almost confluent in the most severely affected regions. In the more recent areas, the patches were irregular and enclosed islands of normal skin (Fig. 3). In all but the mildest lesions, there was a background of erythema and fine telangiectasia which had a cyanotic hue and could be blanched by pressure. On the dorsum of the right foot, 


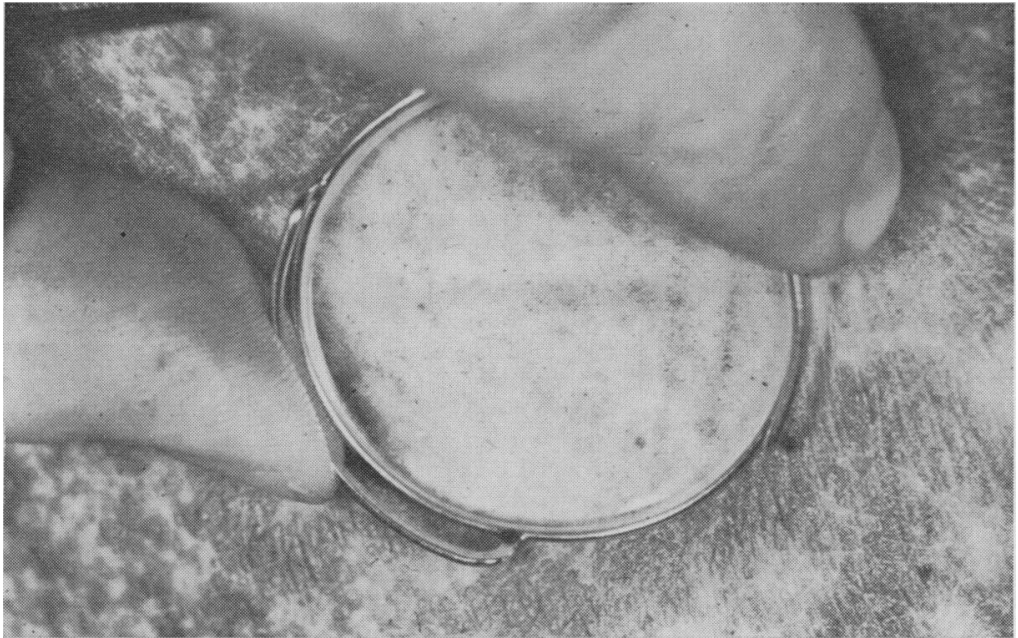

FIG. 2 After firm pressure most of the background telangiectasia can be blanched but many puncta remain

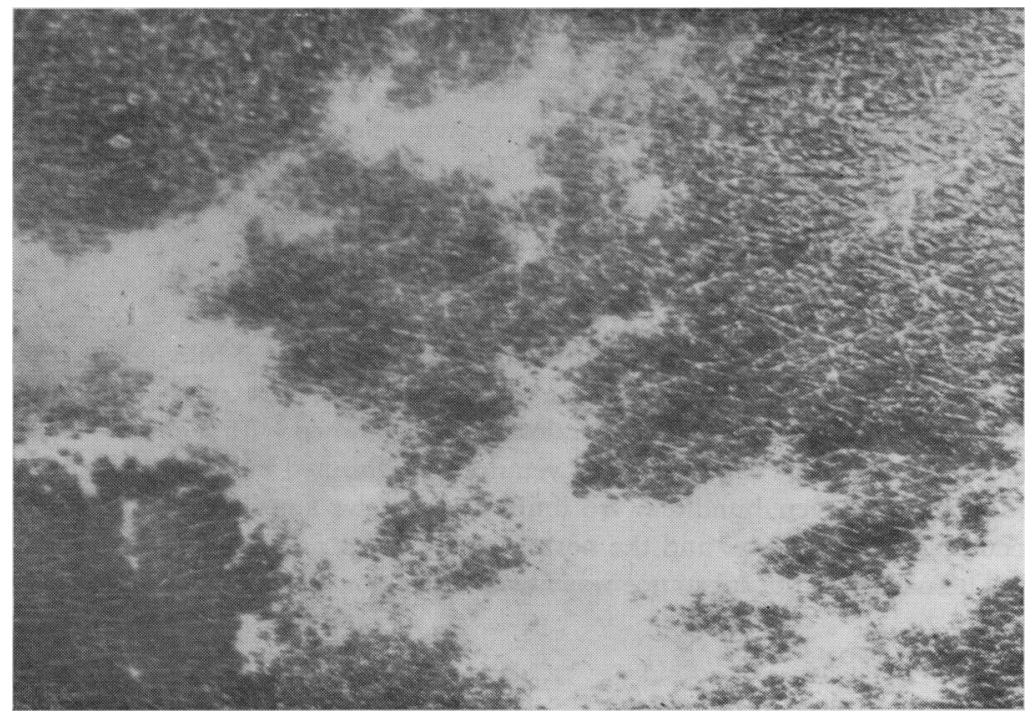

FIG. 3 An area on the thigh, showing areas of involvement enclosing islands of normal skin

however, the colour was bright red and in cold weather the contrast was particularly vivid. The legs were equal in size and there was no significant temperature difference, and similarly the cyanotic and bright red areas registered similar temperatures.

The skin of the thigh was biopsied in April, 1970, with one specimen from a severely affected area and the other from a less involved area. The tissue was fixed in formalin and sectioned after embedding. The most conspicuous feature of the haematoxylin and eosin preparations was the gross dilation of the capillary vessels at the tip of many of the dermal papillae. These microaneurysms distended the papillae and in places the epidermis was thinned over them (Fig. 4, overleaf). The afferent limb of the capillary loop was narrower than normal and surrounded by a thin cuff of amorphous acidophilic and periodic acid-Schiff positive material. The arteries of the dermis seemed to be poorly developed, but the venules draining affected areas were branched, tortuous, irregularly dilated, and cuffed by acidophilic material. Comparable vessels in unaffected areas were not cuffed, and microaneurysms were not seen in the tips of the papillae. Similar vascular abnormalities were seen in the connective tissue sheaths of hair follicles and eccrine sweat glands. 


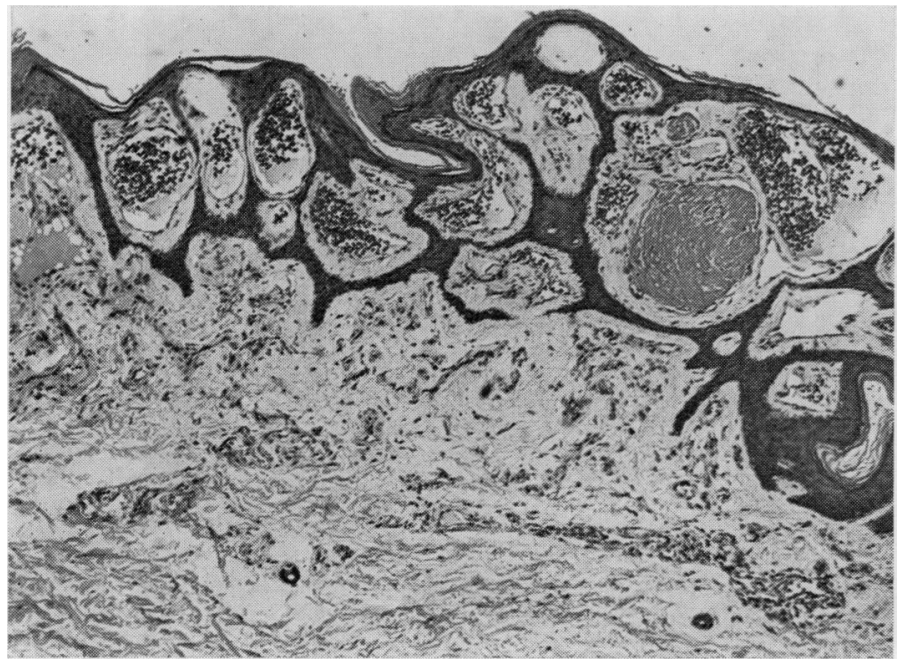

FIG. 4 Section from the more severely affected area, showing widely dilated capillary loops, one containing a thrombus. The epidermis is stretched and raised over the expanded papillae. Haematoxylin and eosin. $\times$ 100

When compared with the biopsy from the less severely affected area, that from the area of advanced change showed larger and more numerous microaneurysms and more severe changes in the subpapillary venous plexus. It also showed a few microaneurysms containing thrombi. With van Gieson's stain, the collagen of the papillary body was somewhat fragmented and a cleft was seen in the collagen network around some capillaries and venules. The reticulin was not altered in distribution, but the superficial elastic fibres were relatively deficient in the unaffected skin and virtually absent in the more severely affected areas.

\section{ELECTRON MIGROSCOPY}

For electron microscopy small pieces of the biopsies were fixed in Millonig's I per cent. buffered osmium tetroxide and embedded in Epon, and thin sections were double-stained with alcoholic uranyl acetate and lead hydroxide. The sections were examined with a Zeiss EM9A microscope.

The endothelial cells of the capillaries and venules were thinned but showed no other abnormality. The subendothelial collagen bundles were infiltrated by the amorphous substance which formed lake-like accumulations in places and the normal array of the collagen fibres was disturbed (Fig. 5, opposite). The nature of the substance was not obvious nor was there any clue to its origin.

\section{OGULAR EXAMINATION}

Small telangiectatic vessels were seen on the right cheek, on the upper eyelid, and in the supraorbital region. There was fullness of the right upper lid. No bruit was audible over the right eye or in the temporal region.

The visual acuity was $6 / 18$ in the right eye, $6 / 9$ with correction, and $6 / 5$ in the left.

Near vision was $\mathrm{N} 6$ in the right eye and $\mathrm{N}_{5}$ in the left.

Ishihara testing showed normal responses in each eye, though the colours were brighter in the left eye. Visual field testing showed full fields in each eye to a 2/1000 white object, though qualitatively the object appeared brighter in the left eye.

\section{Ocular movements}

Abduction was full in the right eye, though all other movements were limited. Depression was most affected (40 per cent. normal), but elevation (6o per cent. normal) and adduction ( 80 per cent. normal) were also limited. Torsion on attempted depression was limited but present.

\section{Pupils}

The right pupil measured $7 \mathrm{~mm}$. and the left $4.5 \mathrm{~mm}$. and there were absent light and near responses 


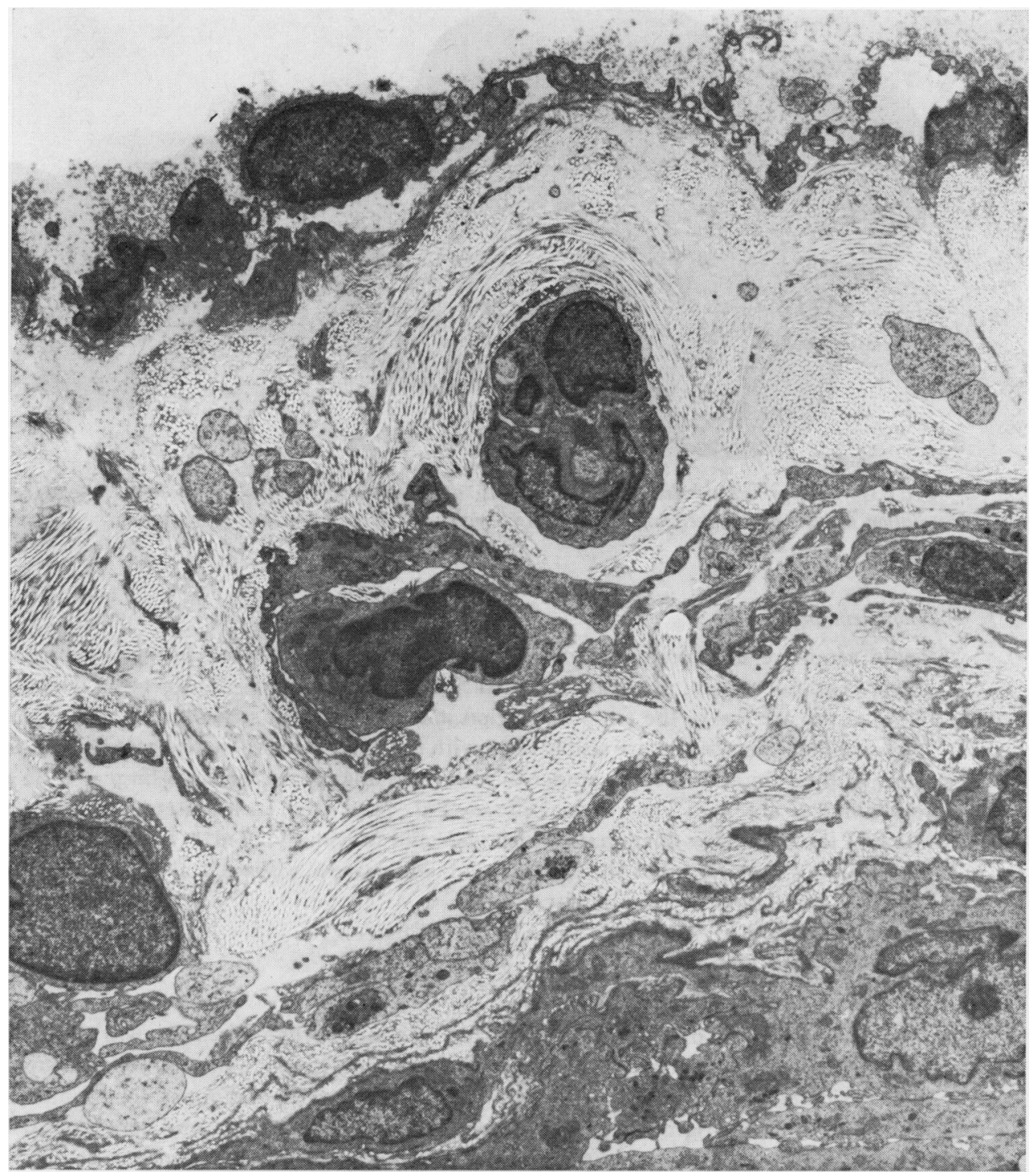

FIG. 5 Electronmicrograph of venule wall. The endothelial cells on the right are rather flattened. The normal arrangement of the subendothelial collagen is disturbed by an amorphous infiltrate. $\times 3,250$

on the right. Repeated instillation of Mecholyl (2.5 per cent.) produced no pupillary constriction.

Slit-lamp examination showed no abnormality of the cornea, anterior chamber, or lens, and the intraocular tension was normal on both sides.

\section{Fundus}

The left eye was normal. The right disc was normal, but in the temporal equatorial region there was an area of diffuse capillary angiomatosis, characterized by numerous discrete capillary angiomata situated mainly at the venous end of the vascular system (Fig. 6, overleaf). Examination in 1970 revealed further angiomatous involvement related to all the other major retinal veins in the periphery. 


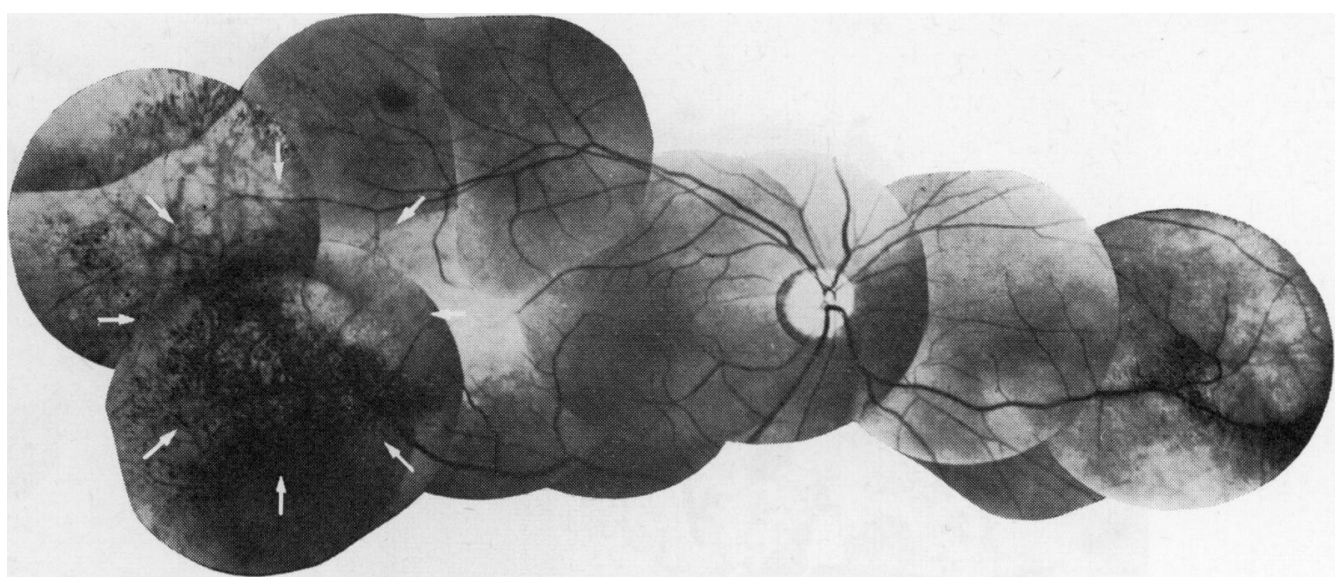

FIG. 6 Copy of colour slides of right fundus, demonstrating angiomatous involvement particularly situated in relation to the veins in the temporal and nasal regions. Arrows represent area studied by fuorescein angiography (see Fig. 7)

\section{Fluorescein angiography}

Rapid sequence fluorescein photography was performed after the intravenous injection of $5 \mathrm{ml}$. 20 per cent. fluorescein, using the modified Zeiss fundus camera. The arterial phase (Fig. $7 a$ ) shows filling of the arteries in the temporal region and these appear straightened and slightly attenuated. A few capillary angiomata are visible filled with the dye. The venous phase (Fig. $7 b$ ) shows irregular filling of the vein and the appearance of numerous angiomata, but in a large area in relation to the vein filling is absent. The residual phase (Fig. 7c), taken to minutes after injection, now shows filling of the remaining angiomata which were not previously filled. The retention of dye indicates a very slow circulation and the discrete globular pattern without leakage of dye demonstrates the integrity of the blood-retina barrier.

\section{NERVOUS SYSTEM}

July, 1950

The right pupil was dilated and showed no reaction to light. There was wasting of the right deltoid, the forearm muscles, and the thenar eminence, with weakness of abduction of the right arm, flexion of the forearm, flexion and extension of the wrist, and opposition, abduction, and flexion of the thumb. The right biceps and supinator reflexes were absent, and both plantar responses were flexor. There was minimal impairment of joint position sense and two point discrimination in the right thumb.

\section{May, 1962}

The right pupil was unchanged. The right corneal reflex and cutaneous sensation in the first division of the right trigeminal nerve were now impaired. Muscle wasting had spread to involve the spinati on the right (Fig. I) with weakness of all muscle groups in the right arm. Cutaneous sensation from $\mathrm{C}_{3}$ to $\mathrm{C} 6$ and position sense in the thumb, index, and middle fingers of the right hand were impaired.

March, 1965

There was no change apart from weakness of all the external ocular muscles on the right with the exception of the lateral rectus.

October, 1970

No further change. 

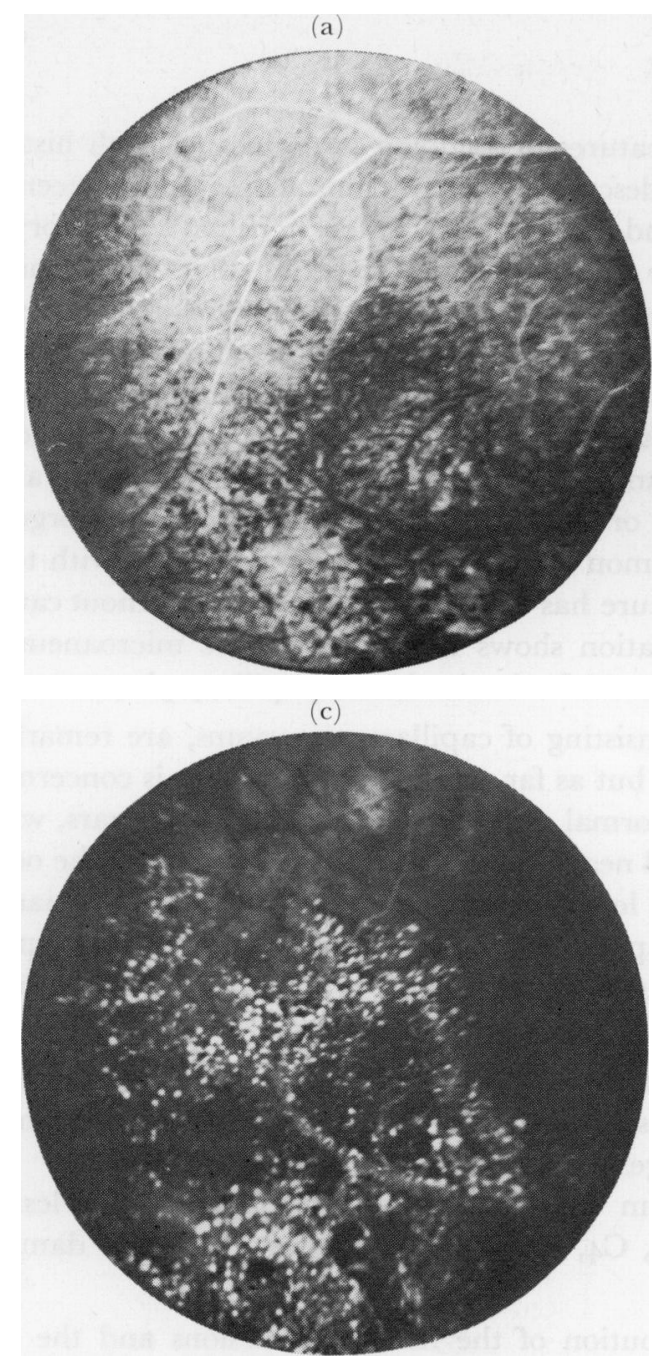

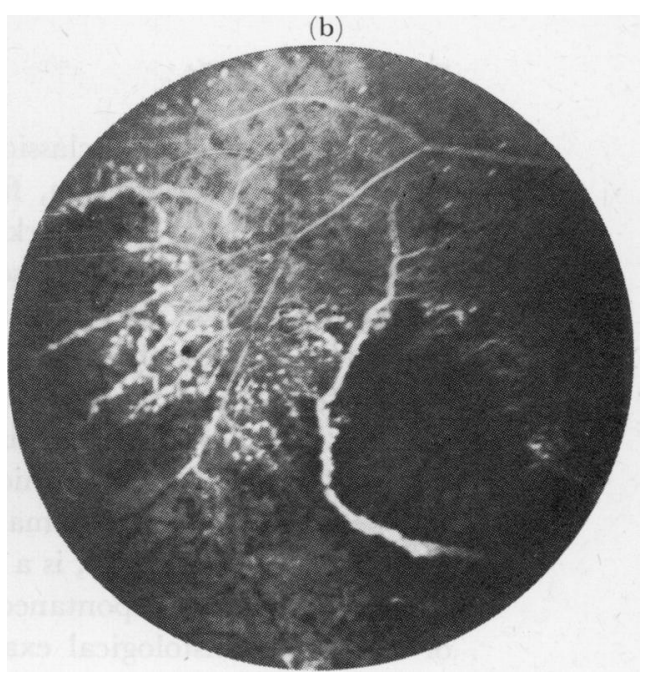

FI G. 7(a) Arterial phase of fluorescein angiogram, demonstrating attenuation of arteries with early filling of some aneurysms. The venous part of the angioma is dark in contrast

FI G. $7(b)$ Arterio-venous phase. More aneurysms are filled and the vein is well filled, demonstrating the irregularity of its wall. A large part of the angioma within the concavity of the vein remains unfilled

FIG. 7(c) Residual phase, 5 minutes after injection. Complete filling of the majority of aneurysms has now occurred but there is no leakage of dye into the retina

LABORATORY INVESTIGATIONS

I950 - Cervical spine $x$ ray - normal

Gerebrospinal fluid - Pressure $120 \mathrm{~mm}$. No cells

Protein $40 \mathrm{mg} . / 100 \mathrm{ml}$. Lange - no change

Myelogram - normal

Wassermann reaction - negative

I965 - Cervical spine $x$ ray - Early degenerative changes

I966 - Caloric test and audiogram - normal

r969- Cervical spine $x$ ray - Extension of spondylotic changes. Narrowing of disc space at $\mathrm{C}_{5}-6$

I970 - Caloric tests and audiogram - normal

Right carotid, vertebral, and subclavian arteriograms - normal

Electroencephalogram - normal, even during manoevures which induced attacks of dizziness Electromyogram - evidence of chronic partial denervation in the muscles of the right arm, maximal in the deltoid, forearm flexors, and abductor pollicis brevis

Nerve conduction studies - motor conduction slower $(45 \mathrm{~m} . / \mathrm{sec}$.) in the forearm segment of the right median nerve, than that in the right ulnar nerve $(66 \mathrm{~m} . \mathrm{sec}$.$) . The median nerve$ sensory action potential on the right was absent, while that of the ulnar was normal. 


\section{Discussion}

This patient shows the classical features of angioma serpiginosum with histological confirmation. This condition, first described by Hutchinson and more recently reviewed by Frain-Bell ( 1957) and Barker and Sachs (1965), differs in its natural history and clinical appearance from the other vascular malformations of the skin. Females are predominantly affected with onset in early childhood, unlike the "port wine" type of telangiectatic naevus it superficially resembles, which is present at birth. The lower limb is most often involved and progression occurs until adolescence with the formation of a ringed, linear, or reticular pattern. The typical and distinctive sign is a large number of purple, red, or copper- के coloured vascular puncta which cannot be completely emptied by pressure and which are $\vec{\circ}$ not petechial. An erythematous or cyanotic background, due to engorgement of the superficial venous plexus, is a common feature and may be associated with telangiectasia. Complete or partial spontaneous cure has occurred in some cases without causing atrophy of the skin. Histological examination shows the puncta to be microaneurysms on the of capillaries of the dermal papillae and of veins in the subpapillary plexus.

The patient's retinal lesions, consisting of capillary aneurysms, are remarkably similar ç to the changes present in the skin, but as far as the nervous system is concerned, the diag- $\frac{O}{工}$ nosis is less certain. The first abnormal sign, noted at the age of 17 years, was dilation of $\vec{c}$ the right pupil, which was followed nearly 20 years later by weakness of the ocular muscles supplied by the third nerve. The lesion of the third nerve was clearly separate from the $\overrightarrow{0}$ extensive damage to the nerve supply of the right arm, which became apparent quite suddenly when the patient was aged 20 years and gradually progressed over the next 20 years.

The weakness and wasting of the right arm, affecting predominantly those muscles supplied by $\mathrm{C}_{5}$ and $\mathrm{C} 6$ and the sensory loss in the same segmental distribution, with absent biceps and supinator reflexes, suggests a lesion affecting these nerve roots. The absence of a sensory action potential from the right index finger places the lesion distal to the dorsal root ganglia. The $\mathrm{C}_{3}, \mathrm{C}_{4}, \mathrm{C}_{7}, \mathrm{C} 8$, and $\mathrm{Tl}$ roots were also damaged but less severely.

The patchy and lengthy distribution of the nerve root lesions and the long 20-year history with a sudden onset make the diagnosis of an angioma affecting these nerve roots or the brachial plexus, almost certain, particularly in view of the cutaneous and retinal lesions. It is probable that the third nerve disorder is due to damage to the nerve itself, as other features of a nuclear lesion are absent (Walsh and Hoyt, i 969).

Russell and Rubinstein (1963) divided the hamartomata of the blood vessels into three groups, the capillary telangiectases, the cavernous angiomata, and the venous and arteriovenous malformations. They considered the haemangioblastomata to be a separate group with neoplastic potential. The pathology of the nerve root lesions in this case is uncertain, but it is likely to be similar to that of the cutaneous and retinal lesions and to represent a disorder of the capillaries and small veins. The normal contrast studies, including myelography and subclavian, vertebral, and carotid angiography, have ruled out any malformation affecting the larger vessels.

It has proved impossible to determine the cause of this patient's feelings of faintness and attacks of loss of consciousness. Normal blood pressure readings during these episodes have ruled out postural hypotension and electroencephalograms were normal, making epileptic phenomena unlikely, as did the failure to respond to anticonvulsants. The fact 
that head-turning often precipitated these attacks raised the question of brain-stem vascular insufficiency, but both vertebral arteries and the basilar artery were normal at angiography and there was no other evidence of brain-stem dysfunction. Full neurootological examination failed to incriminate the vestibular apparatus. It is possible that depression and other psychological factors were playing an important part.

Many associations of vascular anomalies involving the skin, the retina, and the nervous system have previously been described:

(a) The von Hippel-Lindau syndrome represents the association of haemangioblastomata in the cerebellum and retina. Similar tumours may be found in the spinal cord, as well as pancreatic and renal cysts and hypernephromata. The progressive nature of the lesions which commence as capillary angioblastomata (Jesberg, Spencer, and Hoyt, I968), the high morbidity and mortality, and the dominant inheritance of this condition place it in a separate group from the more benign angiomatoses. The retinal lesion is characterized by a progressive capillary angiomatosis with marked exudation, enormous dilation of the feeding vessels, and termination in blindness. Cutaneous naevi have been reported in this syndrome (Hall, 1934-5) but are very rare and are of the "port wine" variety.

(b) The Sturge-Weber syndrome is a developmental anomaly of the intracranial, ocular and cutaneous vascular systems. Angiomatosis of the leptomeninges occurs and also a "port wine" stain on the face, which may spread onto the trunk. Histopathological studies show the dilatation of the capillaries and the venules (Walsh and Hoyt, 1969). The main clinical features are related to the cerebral and ocular involvement which produce seizures and congenital glaucoma respectively. The limbs may be involved with contralateral hemiatrophy but, in some, ipsilateral hemihypertrophy may co-exist with cutaneous angiomatosis (Parkes Weber, 1929). Retinal malformations do not occur, although sheathing and tortuosity of the vessels have been recorded (Walsh and Hoyt) I969,. Extensive choroidal involvement in the absence of retinal abnormalities has been explained embryologically by the different primordial patterns of vascular supply to the two systems (Morgan, ig63).

Closely related to this syndrome, both embryologically and clinically, is the KlippelTrénaunay-Weber syndrome, which is characterized by the presence of naevi, congenital varices, and subcutaneous haemangiomata affecting one limb, usually the arm, in association with local hypertrophy involving the bone and soft tissues. Neurological complications are infrequent and the ocular manifestations include conjunctival telangiectases, choroidal haemangiomata, congenital glaucoma, and retinal varicosities.

(c) Wyburn-Mason (I943a) described a number of cases showing arterio-venous aneurysms of the mid-brain and retina, facial naevi, and mental changes. He cited one case in which cutaneous naevi were present on the trunk and on the back of the leg.

(d) Hereditary haemorrhagic telangiectasia (Rendu-Osler-Weber syndrome) also represents an abnormality of the primordial vascular channels involving only the vessels of smaller calibre. Telangiectases composed of dilated arterioles and capillaries may occur in the skin, mucous membranes, conjunctiva, and retina, and also in the meninges and pia mater of the brain and spinal cord. Malformations in all these sites have a propensity to haemorrhage (Walsh and Hoyt, 1969). 
The present case is different from all these syndromes in a number of respects:

(I) Angioma serpiginosum is a dermatological syndrome which is specific and quite different from the other cutaneous angiomata.

(2) The retinal lesions in this case are unusual and do not conform on clinical or fluor" escein studies to those described in Leber's miliary aneurysms (Wegener, 1969). They more closely resemble the retinal telangiectasia described with hypogammaglobulinaemia (Frenkel and Russe, I967), although in our patient the serum globulins were normal.

The particular features in our case include:

(i) Aneurysmal dilatation involving the retinal arterioles, capillaries, and venules.

(ii) Progressive spread of the lesions without enlargement of the existing ones.

(iii) Preservation of the blood-retina barrier, as shown by fluorescein angiography.

(iv) Attenuation and not hypertrophy of the feeding vessels, with areas of reduced perfusion and the development of 'shunt' vessels.

(v) Similarity of the retinal and cutaneous lesions.

(3) Wyburn-Mason (1943a), in his review of the literature, pointed out that, when retinal arterio-venous aneurysms were associated with similar lesions in the central nervous system, the lesions had all been situated in the mid-brain in those cases in which an adequate neurological examination had been carried out. In the present case, the major anomaly lay unquestionably in the cervical nerve roots and in the third cranial nerve.

Spinal cord angiomata are sometimes associated with cutaneous naevi, which may or may not occupy the corresponding segmental areas on the skin (Wyburn-Mason, 1943b). It is, however, uncommon to find such an extensive cutaneous lesion in a different segmental area, as demonstrated in our case.

The normal pattern of the superficial vessels of the skin is moulded by a variety of influences, including changes in blood flow and viscosity, and the effects of external stimuli and of adjacent tissues, as well as the innate potentialities of endothelial cells (Ryan, I970). The essential pattern is laid down by the third post-natal month (Perera, Kurban, and Ryan, 1970). The course and appearance of angioma serpiginosum suggest that the basic fault is a weakness of the perithelial supporting tissue due to a local defect which has an asymmetrical and mosaic distribution and is gradually revealed by the hydrodynamic stresses within the small vessels in these areas. The precise nature of the defect is not obvious from the abnormalities seen by optical and electron microscopy. A defect in the mesodermal vasoformative tissues would therefore be the most likely explanation for the abnormalities in this case. The similar pattern of progression of the cutaneous, retinal, and nervous system lesions suggests that the vascular defect is the same in the three sites.

\section{Summary}

A case of angioma serpiginosum, complicated by capillary anomalies in the retina and spinal nerve roots, is reported.

The difference between this syndrome and the various conditions in which cutaneous, retinal, and central nervous angiomata have been described, are discussed; it is considered that this may represent a new syndrome.

It is concluded that this case provides evidence to support the view that angioma serpiginosum is due to a congenital defect of the mesodermal vasoformative tissues. 
We should like to thank Mr. Prentice and the Department of Medical Illustration of the National Hospital and Miss K. Phillips of the Department of Neuro-ophthalmology for the Illustrations. We are indebted to Miss Josephine Lace for secretarial assistance.

We are grateful to Mrs. Josephine Diplock for technical assistance with the electron microscopy and to Dr. Elizabeth Ryan for advice on its interpretation.

\section{References}

Barker, L. P., and SACHS, P. M. (1965) Arch. Derm., 92, 6r 3

frain-Bell, w. (1957) Brit. F. Derm., 69, 25I

FRENKEL, M., and RUSSE, H. P. (1967) Amer. 7. Ophthal., 63, 215

hal.L, G. S. (1934-5) J. Neurol. Psychopath., 15, 305

JESBERG, D. O., SPENCER, w. H., and hOYT, w. F. (1968) Arch. Ophthal. (Chicago), 80, 632

MORgan, G. (1963) Proc. roy. Soc. Med., 56, 422

Perera, P., KURban, A. K., and Ryan, T. J. (1970) Brit. 7. Derm., 82, Suppl. 5 "Microvascular

System of the Skin", ed. T. J. Ryan, p. 86

Russell, D. S., and RUBinstein, L. J. (1963) "Pathology of Tumours of the Nervous System". 2nd ed.

Arnold, London

RYAN, T. J. (1970) Brit. F. Derm., 82, Suppl. 5 “Microvascular System of the Skin", ed. T. J. Ryàn, p. 99

WALSH, F. B., and ночт, w. F. (1969) "Clinical Neuro-ophthalmology", 3rd ed. Williams and

Wilkins, Baltimore

WEBER, F. PARKeS (1929) Proc. roy. Soc. Med., 22, 431

WEGENER, J. K. (1969) Acta ophthal. (Kbh.), 47, 108

WYBURN-MASON, R. (1943a) Brain, 66, I63

(1943b) "The Vascular Abnormalities and Tumours of the Spinal Cord and its Membranes". Kimpton, London 